\title{
Insight into REE systematics and age records of metamorphosed garnet from high-resolution trace-element mapping
}

\author{
MATTHIJS SMIT ${ }^{1}$, CARL GUILMETTE ${ }^{2}$, MELANIE
} KIELMAN-SCHMITT $^{3}$, ELLEN KOOIJMAN ${ }^{3}$, LORRAINE TUAL $^{3}$, LOTHAR RATSCHBACHER $^{4}$, ERIK E. SCHERER ${ }^{5}$ AND KLAUS MEZGER ${ }^{6}$

${ }^{1}$ University of British Columbia

${ }^{2}$ Laval University

${ }^{3}$ Swedish Museum of Natural History

${ }^{4}$ Institute of Geology, TU Bergakademie Freiberg

${ }^{5}$ Westfälische Wilhelms-Universität

${ }^{6}$ University of Bern

Presenting Author: msmit@eoas.ubc.ca

Garnet chronology (Lu-Hf, Sm-Nd), and REE-based linkage between garnet and chronometric accessory phases, are powerful means of placing garnet's rich metamorphic record in time. The interpretation of REE compositions and zoning of garnet is crucial in either approach. Nevertheless, it can be difficult to distinguish between primary growth features and the effects of diffusive re-equilibration, especially because there are substantial uncertainties regarding the effects of REE diffusion on zoning and chronology [1]. Taking advantage of new capabilities in trace-element mapping, we investigated the REE composition and zoning of garnet in high-grade rocks that underwent (ultra)high temperature metamorphism on different time scales.

Garnet grains were mapped for trace elements using an ArF excimer laser ablation system with a small-cell geometry and rectangular-spot ablation capabilities, coupled to a sector-field ICP-MS. The grains typically show step-wise concentric zoning, with large chemical gradients on the scale of micrometers and angular geometries that mimic crystal faces. Some grains preserve oscillatory zoning, locally with a very short $(10-\mu \mathrm{m})$ wave length. Cloudy and smooth zoning coexists with sharper features; the general interpretation of such zoning as resulting from volume diffusion is non-unique at best. The retention of zoning provides important constraints on the interpretation of the Lu-Hf ages obtained for these samples.

The observations made here and elsewhere [2] show that the (H)REE systematics of natural garnet are robust to thermal overprinting, far more so than experimental constraints on HREE diffusivity would predict [3]. This conforms to the hypothesis that, different from experiments, REE diffusion in natural garnet is controlled by sluggish diffusion kinetics of the trivalent cation that REE is coupled with [4]. The analyzed garnet grains underwent thermal histories that are on the extreme end of what is known for crustal rocks. The preservation of prograde features thus suggests that the effects of REE volume diffusion on REE zoning and Lu-Hf ages of natural garnet are generally limited, if not insignificant.

[1] Baxter et al. (2017) RiMG 83, 469-533.

[2] Rubatto et al. (2020) CMP 175, 61. 